\title{
The Salience Network: A Neural System for Perceiving and Responding to Homeostatic Demands
}

\author{
DWilliam W. Seeley ${ }^{1,2}$ \\ ${ }^{1}$ Memory and Aging Center, Department of Neurology, and ${ }^{2}$ Department of Pathology, University of California, San Francisco, California 94143
}

The term "salience network" refers to a suite of brain regions whose cortical hubs are the anterior cingulate and ventral anterior insular (i.e., frontoinsular) cortices. This network, which also includes nodes in the amygdala, hypothalamus, ventral striatum, thalamus, and specific brainstem nuclei, coactivates in response to diverse experimental tasks and conditions, suggesting a domain-general function. In the 12 years since its initial description, the salience network has been extensively studied, using diverse methods, concepts, and mammalian species, including healthy and diseased humans across the lifespan. Despite this large and growing body of research, the essential functions of the salience network remain uncertain. In this paper, which makes no attempt to comprehensively review this literature, I describe the circumstances surrounding the initial discovery, conceptualization, and naming of the salience network, highlighting aspects that may be unfamiliar to many readers. I then discuss some of the key advances provided by subsequent research and conclude by posing a few of the questions that remain to be explored.

In 2003, when my University of California, San Francisco (UCSF) behavioral neurology fellowship began, the human brain mapping community was just beginning to recognize that regional low-frequency BOLD signal fluctuations were correlated, within functional-anatomical systems, even while subjects lay quietly awake in the MRI scanner (Biswal et al., 1995; Greicius et al., 2003). To some, this seemed like nonsense (most likely "noise"), to others it was magic (something closer to voodoo), and to still others it was a revelation. To me, a neurologist and aspiring neuroanatomist, the results were breathtaking. Here was an opportunity to study large-scale brain networks and bridge the gap from axonal tracer studies, performed in nonhuman primates, to humans. The potential of the advance was clear, but I needed some convincing about the methods. I learned what I could and sought guidance from another early-career behavioral neurologist, Michael Greicius, who, with Vinod Menon and his team at Stanford, had just published the seminal paper identifying the "default mode network" (DMN) using "resting state fMRI" (Greicius et al., 2003). For Greicius, whose foresight was remarkable, the motivation to study the DMN arose, at least in part, from a clinical interest in Alzheimer's disease (AD), which targets many of the structures that compose the DMN.

I too had a specific agenda. My clinical training had exposed me to patients with a little-known disorder called frontotemporal dementia (FTD), which would become my major research interest. My mentor, Bruce Miller, was one of the few American neu-

Received July 14, 2019; revised 0ct. 15, 2019; accepted 0ct. 23, 2019.

I thank my patients and their families and caregivers for their enduring contributions to neuroscience research; and Michael Greicius, John Allman, Patrick Hof, Bud Craig, David Perry, Virginia Sturm, Juan Zhou, Marsel Mesulam, Stephen DeArmond, Bruce Miller, and many others for thoughtful discussions and other forms of support related to this manuscript.

The author declares no competing financial interests.

Correspondence should be addressed to William W. Seeley at wseeley@memory.ucsf.edu

https://doi.org/10.1523/JNEUROSCI.1138-17.2019

Copyright $\odot 2019$ the authors rologists who had been writing about FTD over the preceding decade. Patients with the behavioral variant (bvFTD) were known to slowly lose specialized social-emotional capacities, such as grace, tact, drive, and empathy, but new research had begun to suggest additional deficits in nociceptive and autonomic processing (Snowden et al., 2001). Fascinated by this phenomenology, I wondered whether there might be a unifying functional deficit that could help to explain the syndrome's diverse manifestations. Coworkers at UCSF had just revealed, using voxel-based morphometry, that bvFTD was associated with prominent atrophy in the ACC and anterior insular cortex (aINS) (Rosen et al., 2002). Their observations led me to read across a range of unfamiliar fields. I learned that the ACC and aINS contain subregions featuring cytoarchitecturally related agranular cortices (lacking a visible layer 4) that provide a transition from peri-allocortex to pro-isocortex (Mesulam and Mufson, 1982a; Ongür et al., 2003; Heimer and Van Hoesen, 2006). In rodents and monkeys, homologous regions are interconnected with limbic, subcortical, and brainstem sites involved in autonomic processing and emotion (Carmichael and Price, 1996; Saper, 2002). Task-based fMRI studies from the preceding $\sim 5$ years had shown, collectively, that ACC and aINS coactivate in the context of diverse tasks and conditions, ranging from those designed to induce thirst, hunger, pain, bladder distention, embarrassment, and uncertainty to those eliciting amusement, compassion, tenderness, and humor (Craig, 2002; Critchley, 2005). Many authors in their respective fields had begun to write about the ACC and aINS as key hubs of a [fill-in-the-blank] network, where the blank could be filled by almost anything a human might care about. Other authors, particularly those from a more anatomical tradition, were beginning to write about the ACC and aINS as domain-general regions that participate in emotion, autonomic functions, or self-awareness (Craig, 2002; Saper, 2002; Critchley, 2005; Heimer and Van Hoesen, 2006). 
A

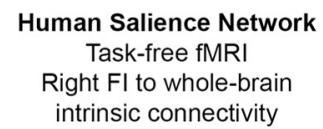

B

VEN distribution

Primary regions where

VENs are identified in humans

C

bvFTD atrophy

Overlap of atrophy

in 9 most common

neuropathological

D causes of bvFTD

Mouse Salience Network AAV injection, Area PL Allen Institute for Brain Science
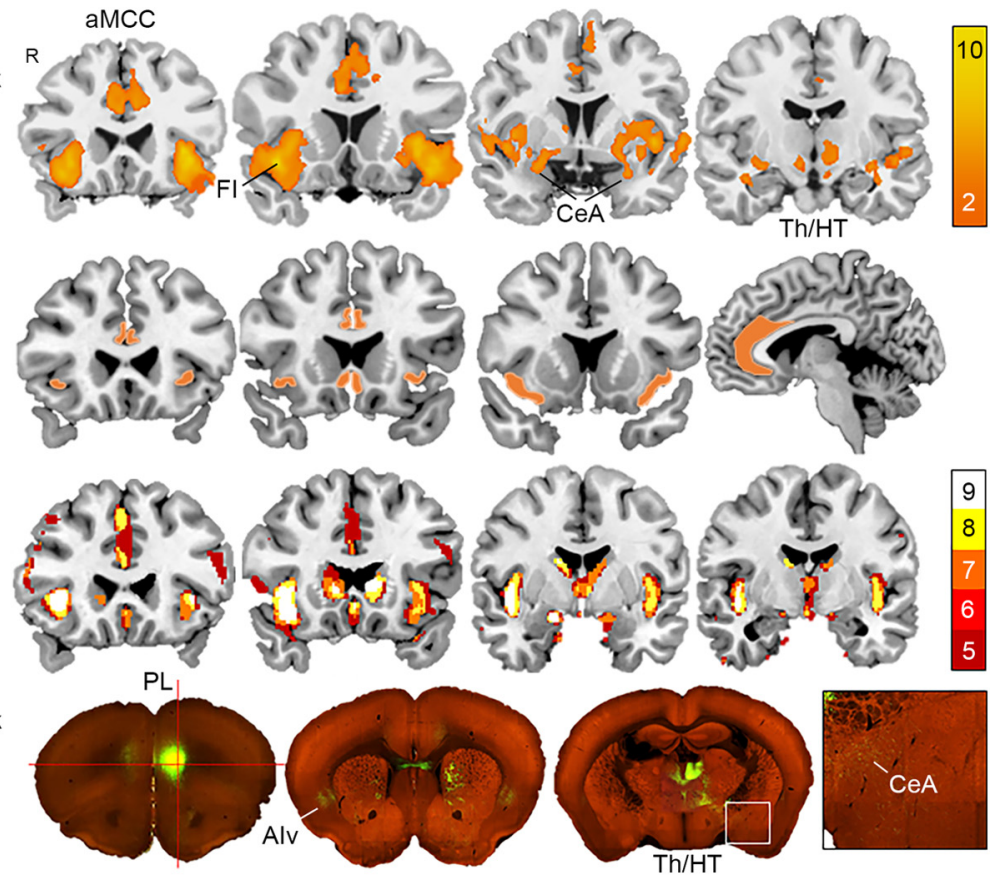

Figure 1. The human salience network $(\boldsymbol{A})$, topography of the VENs $(\boldsymbol{B})$, and the atrophy pattern in bvFTD $(\boldsymbol{C})$ strongly overlap. $\boldsymbol{D}$, A homologous network is elicited by injecting adeno-associated virus (AAV) into mouse prelimbic area (area PL), which produces layer 5 labeling in area ventral anterior insula area (Alv), as well as in the ventral striatum, dorsomedial thalamus (TH), hypothalamus (HT), and central amygdala (CeA). A, Map adapted with permission from Seeley et al. (2007b). B, Map is rendered by the author. C, Map adapted with permission from Perry et al. (2017). D, Map assembled using the Allen Mouse Brain Connectivity Atlas.

Patients with bvFTD have limited insight into their deficits, but their family members taught me that bvFTD-related "personality change" takes many forms. Work and household duties lapse or require constant encouragement. Patients show little interest in their spouse's feelings, even if the spouse has been injured or diagnosed with a serious illness. Social boundaries and conventions lose their influence on behavior, resulting in myriad transgressions. Patients may become difficult to embarrass, humorless, and insensitive to satiety, eating as long as food is present. In later stages, even immediate-impact stressors, such as thirst, ambient temperature extremes, or ongoing tissue damage, elicit muted or absent responses. Together, the stories I heard evoked a patient whose usual cares, including their own social errors, could elicit neither an internal sense of concern nor the usual corrective actions. In essence, nothing important mattered anymore, yet both restraint (the brakes) and drive (the gas pedal) were broken. Why? What lesion could explain this deficit?

The next step along the path was the least expected. In 2004, I attended a lecture by John Allman, an evolutionary biologist who was visiting UCSF. He presented recent work on a curious population of large layer 5 projection neurons, called von Economo neurons (VENs), which, he proposed, had become specialized to support social functioning (Allman et al., 2001). What captured my attention, however, was the topographic distribution of these cells: virtually all of them, Allman explained, were concentrated in the domes of the ACC (agranular subareas 24a and b) and ventral (agranular) aINS, also known (and henceforward referred to) as the frontoinsular cortex (Fig. 1B) (von Economo, 1926; Nimchinsky et al., 1995). On the day of Allman's lecture, three related hypotheses began to take shape. First, I imagined that bvFTD might begin in the VENs, whose specialized nature might somehow confer vulnerability to disease. Second, I wondered whether the VENs and their home regions might anchor a largescale network that could (now) be mapped in living humans (with "resting-state fMRI"). Third, I hypothesized that degeneration of this VEN-related network might drive the core symptoms seen in bvFTD.

Within days of Allman's lecture, he and I were on airplanes bound for Washington, DC, where we would spend a week exploring the idea that bvFTD might target the VENs. The YakovlevHalleem Collection, an extraordinary archive of whole-mounted human brain sections capturing a broad range of diseases, contained a few patients with FTD (diagnosed decades earlier as "Pick's disease"). We spent the week poring over the materials, trying to find what few VENs may have remained in those FTD sections, mostly without success (Seeley et al., 2007a). I returned to California, energized, and asked Greicius: what would happen if we mapped the regions whose BOLD signals correlate with those of the (VEN-rich) frontoinsular cortex? We designed a study in healthy young adults, the results came in, and the "salience network" was born (Fig. 1A) (Seeley et al., 2007b). Born with it, a sort of fraternal twin, was a more familiar "executive-control network," a lateral frontoparietal system made up of regions known to support working memory, executive function, and cognitive control processes. The strength of these networks, we showed, could be linked to emotional and cognitive data obtained outside the scanner. The salience network showed stronger intranetwork regional BOLD correlations in subjects with high prescan anxiety (but had no relationship to executive functioning). Executive-control network regions showed tighter coupling in patients with better executive task performance (but no relationship to anxiety). This double dissociation raised the possibility that networks measured in this way might have a significant "trait component." The final manuscript made only passing reference to bvFTD and VENs despite the outsized roles they played in motivating the study. It was a systems neuroscience experiment performed with a clinical goal in mind. It also convinced me, Greicius, and others that these so-called resting-state networks contained important neurobio- 
logical information. Likewise, the presence of a human, VENenriched network intensified my interest in whether VENs were targeted in bvFTD, a hunch that has been confirmed (Seeley et al., 2006; Kim et al., 2012; Nana et al., 2019) and replicated by other laboratories (Santillo et al., 2013; Santillo and Englund, 2014; Yang et al., 2017). Subsequent work also confirmed the consistency of salience network involvement across the diverse neuropathological causes of bvFTD (Fig. 1C) (Perry et al., 2017).

A brief aside on terms. At the time of the paper, we named the salience network based on our impressions of what the ACC, aINS, and their interacting partners might collectively do. The concept then, as it remains for me now, was that the frontoinsula was a major afferent cortical hub for perceiving visceroautonomic feedback, whereas the ACC was the efferent hub responsible for generating relevant visceral, autonomic, behavioral, and cognitive responses. Through interactions with each other, these regions could form a sort of information processing loop for representing and responding to homeostatically relevant internal or external stimuli and imbuing these stimuli with emotional weight. These ideas represented a synthesis of many related prior notions put forth by thought leaders in the field (Mesulam and Mufson, 1982b; Craig, 2002, 2003; Saper, 2002; Critchley, 2005; Heimer and Van Hoesen, 2006). We chose "salience" as a substitute for "homeostatic relevance" because "homeostatic relevance network" seemed a bit of a mouthful and salience captured the essence of the concept. Other terms introduced in the paper (in addition to the name of the fraternal twin) included "intrinsic connectivity network," as an alternative to "resting state network," and "task-free fMRI," as an alternative to "resting-state fMRI." Our hope was to push the field away from the idea that mental inactivity (i.e., "rest") was the key to identifying networks in this way.

The salience network paper was published shortly after Nico Dosenbach, Steve Petersen, and their colleagues had identified a topographically similar pattern of brain regions using a different approach (Dosenbach et al., 2006). These regions, which make up a more dorsal and opercular frontal and anterior parietal pattern that nonetheless includes the anterior mid-cingulate and aINS cortices, were identified based on their activation during specific phases of 10 diverse task-based fMRI studies. For years, many researchers understood their work and ours to be describing the same system. Slowly, the distinction between the two networks became clearer (Power et al., 2011; Touroutoglou et al., 2012; Nomi et al., 2016). The network identified by Dosenbach et al. (2006), now often referred to as the "cingulo-opercular taskcontrol network," is anchored by the dorsal aINS (a nearly VENfree aINS subregion) and the adjacent frontal operculum and appears critical for task set initiation and maintenance, perhaps by providing the sustained vigilance or "tonic alertness" (Sadaghiani et al., 2010) required to enter and stay in a behavioral or cognitive set. In contrast, the nearby salience network is anchored by the more ventral frontoinsula (where VENs are abundantly found), and represents, in my way of thinking, the homeostatic system whose job is, in part, to engage the task-control network so it can (1) maintain the most relevant task set for as long as the salient stimulus complex remains or (2) orchestrate switching to a new task set (and relevant network configuration) in response to shifts in the salience landscape (Menon and Uddin, 2010). Looking back at the Dosenbach et al. (2006) study, one can already see the importance of the frontoinsula in salience processing; across their several analyses, the frontoinsula appears only in the map derived from behavioral errors, one major form of sa- lience that the network must represent to support the guidance and tuning of behavior.

What has research performed since 2007 taught us about the salience network, its functions, and the consequences of its dysfunction? The volume of relevant studies is overwhelming, so I have selected a few favorites, each representing a different method. An important meta-analysis, performed in 2013, showed that the ACC and aINS respond to salience independent of value (Bartra et al., 2013). This observation, made by aggregating fMRI data from $>206$ studies, confirmed a key premise of the salience network concept: that the network should respond to homeostatically relevant stimuli and outcomes whether their valence is negative (penalizing) or positive (reinforcing). Another key question concerns whether the network operates under substantial influence of major ascending neuromodulatory systems. Of these, the most natural allies are the following: (1) the noradrenergic system, anchored by the locus ceruleus and thought to increase signal-to-noise within cortical networks in response to salience; and (2) the mesocorticolimbic dopamine system, anchored by the ventral tegmental area and thought to provide signals related to error, reward, and novelty. Regarding the noradrenergic system, one inventive study exposed healthy subjects to an emotion-eliciting video clip (of a violent bar brawl) after treatment with propranolol (a beta-adrenergic receptor blocker) or placebo (Hermans et al., 2011). They found that beta-receptor blockade significantly attenuated the salience network synchrony normally induced by the film. Regarding the dopamine system, a recent experiment evaluated large-scale network connectivity after dopamine depletion via acute phenylalanine and tyrosine depletion (Shafiei et al., 2019), which produced a conspicuous reduction in connectivity between the salience network and other parts of the brain. Optogenetic experiments in mice suggest that dopaminergic neurons in the dorsal raphe nucleus may also play a role in behavioral responses to salience (Cho et al., 2017). Related studies of salience network function have focused on the network's proposed role in awareness and even consciousness. For example, one study identified a dorsal pontine region commonly injured across a broad sample of neurological lesion patients who presented with coma (i.e., disruptions in conscious wakefulness) (Fischer et al., 2016). They went on to show that this region, near the locus ceruleus and adjacent medial parabrachial nucleus (both key nodes for autonomic integration), featured the ACC and frontoinsula as its major cortical functional connections. Many groups, including ours, have highlighted the role of the salience network in autonomic processing (Critchley et al., 2011; Beissner et al., 2013; Guo et al., 2016; Sturm et al., 2018), but it has proved challenging to disentangle representations related to homeostatic salience from those that drive autonomic responses to that salience. Indeed, in a remarkable study of awake, behaving patients with epilepsy who underwent presurgical monitoring and electrophysiological mapping, direct stimulation of the ACC elicited not only an internal sense of a looming challenge but also heart rate acceleration and, perhaps most strikingly, the will to act and persevere in response to the perceived challenge (Parvizi et al., 2013). Overall, the studies reviewed here support the idea that the salience network hubs, whatever else they may be doing, are intimate partners for conscious integration of autonomic feedback and responses with internal goals and environmental demands.

One could argue that no ecological niche places more demands on the salience network, as conceived here, than a complex social environment. In the thick of social living, short- and long-term goals and actions compete against a backdrop of $N$ 
dynamic, interacting, multidimensional agents (i.e., $N$ other humans), where $N$ ranges from 1 to 100 s or even 1000 s now (through social media) in a given moment. Add the need to integrate learned social rules, hierarchies, and contingencies, and you have a daunting challenge for any system. In this light, it has been intriguing that the most convincing clinical examples of salience network dysfunction are disorders of social-emotional function. bvFTD is perhaps the best-documented example, but schizophrenia, bipolar disorder, major depression, attention-deficit/ hyperactivity, anxiety states, autism spectrum, and substance abuse disorders have now all been linked to volume loss or altered connectivity in salience network regions (Goodkind et al., 2015; Sha et al., 2019). These findings add support to the notion that salience network hubs play a domain-general function that can somehow be disrupted to produce diverse clinical manifestations. The specific manifestations may depend on the following: (1) the micro-anatomical targets (neuron types and circuit elements), (2) physiological details (affected channels or modulatory neurotransmitters), or (3) the other brain areas involved. Conversely, some neuropsychiatric diseases, most notably $\mathrm{AD}$ and Williams' syndrome, appear to involve a gain of socialemotional sensitivity that relates to intensification of salience network connectivity, structure, or function (Zhou et al., 2010; Jabbi et al., 2012; Zhou and Seeley, 2014). Clearly, there is more to learn about the healthy salience network by studying the salience network-opathies and other disorders in which the salience network is perturbed, even when another network remains the primary locus of dysfunction.

After Greicius and his colleagues published the 2003 DMN paper (Greicius et al., 2003), they and now many others went on to show that Alzheimer-type dementia is indeed associated with DMN-localized atrophy, hypometabolism, and disrupted intrinsic connectivity (Greicius et al., 2004; Buckner et al., 2005). Following suit, we showed similar findings for bvFTD and the salience network (Zhou et al., 2010). By around that time, it seemed most parsimonious to think that the pairing of a neurodegenerative syndrome to a large-scale network would not be limited to $\mathrm{AD}$ and bvFTD. In the behavioral neurology clinic at UCSF, we routinely see patients with a diversity of clinical syndromes, including AD-type dementia and bvFTD, but also other FTD syndromes that affect language or movement. In a series of subsequent studies, we showed that each of these syndromes is associated with atrophy that mirrors a specific large-scale network, with associated connectivity disruption (Seeley et al., 2009; Gardner et al., 2013; Guo et al., 2013). Later work revealed that a region's connectivity to a likely region-of-onset, or "epicenter," was a strong predictor of that region's vulnerability to disease, suggesting that trans-synaptic spreading may account, at least in part, for the network-based atrophy observed (Zhou et al., 2012). Ongoing research continues to advance this frontier (IturriaMedina et al., 2014; Raj et al., 2015; Torok et al., 2018; Brown et al., 2019).

Where should salience network research go from here? Fundamental questions remain about what core domaingeneral function or functions the salience network performs. Sorting through these questions may require human neuroscience techniques that afford millisecond temporal resolution in combination with more sophisticated behavioral paradigms and continuous multichannel recordings of autonomic and other emotion-relevant data (facial expression, vocalization, etc.). Framed by this knowledge, modern circuit dissection tools could be used to tease apart some of the network's most basic functions, leaning on the overall conservation of the salience net- work in laboratory mammals (Fig. 1D) and the opportunities for causal manipulation and microscale in vivo resolution. The knowledge gained from these convergent approaches may facilitate differentiation of salience network-related clinical disorders based on their distinct pathophysiological profiles and mechanisms. This deeper understanding may, in turn, lead to a more precise understanding of the microanatomy and neurochemistry of these disorders. Now, with the advent of single-cell sequencing approaches, researchers can begin to explore disease-specific links between salience network deficits and changes in the number, states, or functioning of specific human neuronal and glial cell types. The road ahead promises to teach us a great deal about ourselves and how our brains handle the moments that matter most in our lives. More importantly, we can hope to learn enough to help those who lack or lose this fundamental human capacity.

\section{References}

Allman JM, Hakeem A, Erwin JM, Nimchinsky E, Hof P (2001) The anterior cingulate cortex: the evolution of an interface between emotion and cognition. Ann N Y Acad Sci 935:107-117.

Bartra O, McGuire JT, Kable JW (2013) The valuation system: a coordinatebased meta-analysis of BOLD fMRI experiments examining neural correlates of subjective value. Neuroimage 76:412-427.

Beissner F, Meissner K, Bär KJ, Napadow V (2013) The autonomic brain: an activation likelihood estimation meta-analysis for central processing of autonomic function. J Neurosci 33:10503-10511.

Biswal B, Yetkin FZ, Haughton VM, Hyde JS (1995) Functional connectivity in the motor cortex of resting human brain using echo-planar MRI. Magn Reson Med 34:537-541.

Brown JA, Deng J, Neuhaus J, Sible IJ, Sias AC, Lee SE, Kornak J, Marx GA, Karydas AM, Spina S, Grinberg LT, Coppola G, Geschwind DH, Kramer JH, Gorno-Tempini ML, Miller BL, Rosen HJ, Seeley WW (2019) Patient-tailored, connectivity-based forecasts of spreading brain atrophy. Neuron. Advance online publication. Retrieved September 18, 2019. doi: 10.1016/j.neuron.2019.08.037.

Buckner RL, Snyder AZ, Shannon BJ, LaRossa G, Sachs R, Fotenos AF, Sheline YI, Klunk WE, Mathis CA, Morris JC, Mintun MA (2005) Molecular, structural, and functional characterization of Alzheimer's disease: evidence for a relationship between default activity, amyloid, and memory. J Neurosci 25:7709-7717.

Carmichael ST, Price JL (1996) Connectional networks within the orbital and medial prefrontal cortex of macaque monkeys. J Comp Neurol 371: 179-207.

Cho JR, Treweek JB, Robinson JE, Xiao C, Bremner LR, Greenbaum A, Gradinaru V (2017) Dorsal raphe dopamine neurons modulate arousal and promote wakefulness by salient stimuli. Neuron 94:1205-1219.e8.

Craig AD (2002) How do you feel? Interoception: the sense of the physiological condition of the body. Nat Rev Neurosci 3:655-666.

Craig AD (2003) Interoception: the sense of the physiological condition of the body. Curr Opin Neurobiol 13:500-505.

Critchley HD (2005) Neural mechanisms of autonomic, affective, and cognitive integration. J Comp Neurol 493:154-166.

Critchley HD, Nagai Y, Gray MA, Mathias CJ (2011) Dissecting axes of autonomic control in humans: insights from neuroimaging. Auton Neurosci 161:34-42.

Dosenbach NU, Visscher KM, Palmer ED, Miezin FM, Wenger KK, Kang HC, Burgund ED, Grimes AL, Schlaggar BL, Petersen SE (2006) A core system for the implementation of task sets. Neuron 50:799-812.

Fischer DB, Boes AD, Demertzi A, Evrard HC, Laureys S, Edlow BL, Liu H, Saper CB, Pascual-Leone A, Fox MD, Geerling JC (2016) A human brain network derived from coma-causing brainstem lesions. Neurology 87 2427-2434.

Gardner RC, Boxer AL, Trujillo A, Mirsky JB, Guo CC, Gennatas ED, Heuer HW, Fine E, Zhou J, Kramer JH, Miller BL, Seeley WW (2013) Intrinsic connectivity network disruption in progressive supranuclear palsy. Ann Neurol 73:603-616.

Goodkind M, Eickhoff SB, Oathes DJ, Jiang Y, Chang A, Jones-Hagata LB, Ortega BN, Zaiko YV, Roach EL, Korgaonkar MS, Grieve SM, GalatzerLevy I, Fox PT, Etkin A (2015) Identification of a common neurobiological substrate for mental illness. JAMA Psychiatry 72:305-315. 
Greicius MD, Krasnow B, Reiss AL, Menon V (2003) Functional connectivity in the resting brain: a network analysis of the default mode hypothesis. Proc Natl Acad Sci U S A 100:253-258.

Greicius MD, Srivastava G, Reiss AL, Menon V (2004) Default-mode network activity distinguishes Alzheimer's disease from healthy aging: evidence from functional MRI. Proc Natl Acad Sci U S A 101:4637-4642.

Guo CC, Gorno-Tempini ML, Gesierich B, Henry M, Trujillo A, Shany-Ur T, Jovicich J, Robinson SD, Kramer JH, Rankin KP, Miller BL, Seeley WW (2013) Anterior temporal lobe degeneration produces widespread network-driven dysfunction. Brain 136:2979-2991.

Guo CC, Sturm VE, Zhou J, Gennatas ED, Trujillo AJ, Hua AY, Crawford R, Stables L, Kramer JH, Rankin K, Levenson RW, Rosen HJ, Miller BL, Seeley WW (2016) Dominant hemisphere lateralization of cortical parasympathetic control as revealed by frontotemporal dementia. Proc Natl Acad Sci U S A 113:E2430-E2439.

Heimer L, Van Hoesen GW (2006) The limbic lobe and its output channels: implications for emotional functions and adaptive behavior. Neurosci Biobehav Rev 30:126-147.

Hermans EJ, van Marle HJ, Ossewaarde L, Henckens MJ, Qin S, van Kesteren MT, Schoots VC, Cousijn H, Rijpkema M, Oostenveld R, Fernández G (2011) Stress-related noradrenergic activity prompts large-scale neural network reconfiguration. Science 334:1151-1153.

Iturria-Medina Y, Sotero RC, Toussaint PJ, Evans AC (2014) Epidemic spreading model to characterize misfolded proteins propagation in aging and associated neurodegenerative disorders. PLoS Comput Biol 10:e1003956.

Jabbi M, Kippenhan JS, Kohn P, Marenco S, Mervis CB, Morris CA, MeyerLindenberg A, Berman KF (2012) The Williams syndrome chromosome 7q11.23 hemideletion confers hypersocial, anxious personality coupled with altered insula structure and function. Proc Natl Acad Sci U S A 109:E860-E866.

Kim EJ, Sidhu M, Gaus SE, Huang EJ, Hof PR, Miller BL, DeArmond SJ, Seeley WW (2012) Selective frontoinsular von Economo neuron and fork cell loss in early behavioral variant frontotemporal dementia. Cereb Cortex 22:251-259.

Menon V, Uddin LQ (2010) Saliency, switching, attention and control: a network model of insula function. Brain Struct Funct 214:655-667.

Mesulam MM, Mufson EJ (1982a) Insula of the old world monkey: I. Architectonics in the insulo-orbito-temporal component of the paralimbic brain. J Comp Neurol 212:1-22.

Mesulam MM, Mufson EJ (1982b) Insula of the old world monkey: III. Efferent cortical output and comments on function. J Comp Neurol 212:38-52.

Nana AL, Sidhu M, Gaus SE, Hwang JL, Li L, Park Y, Kim EJ, Pasquini L, Allen IE, Rankin KP, Toller G, Kramer JH, Geschwind DH, Coppola G, Huang EJ, Grinberg LT, Miller BL, Seeley WW (2019) Neurons selectively targeted in frontotemporal dementia reveal early stage TDP-43 pathobiology. Acta Neuropathol 137:27-46.

Nimchinsky EA, Vogt BA, Morrison JH, Hof PR (1995) Spindle neurons of the human anterior cingulate cortex. J Comp Neurol 355:27-37.

Nomi JS, Farrant K, Damaraju E, Rachakonda S, Calhoun VD, Uddin LQ (2016) Dynamic functional network connectivity reveals unique and overlapping profiles of insula subdivisions. Hum Brain Mapp 37: $1770-1787$.

Ongür D, Ferry AT, Price JL (2003) Architectonic subdivision of the human orbital and medial prefrontal cortex. J Comp Neurol 460:425-449.

Parvizi J, Rangarajan V, Shirer WR, Desai N, Greicius MD (2013) The will to persevere induced by electrical stimulation of the human cingulate gyrus. Neuron 80:1359-1367.

Perry DC, Brown JA, Possin KL, Datta S, Trujillo A, Radke A, Karydas A, Kornak J, Sias AC, Rabinovici GD, Gorno-Tempini ML, Boxer AL, De May M, Rankin KP, Sturm VE, Lee SE, Matthews BR, Kao AW, Vossel KA, Tartaglia MC, et al. (2017) Clinicopathological correlations in behavioural variant frontotemporal dementia. Brain 140:3329-3345.

Power JD, Cohen AL, Nelson SM, Wig GS, Barnes KA, Church JA, Vogel AC, Laumann TO, Miezin FM, Schlaggar BL, Petersen SE (2011) Functional network organization of the human brain. Neuron 72:665-678.

Raj A, LoCastro E, Kuceyeski A, Tosun D, Relkin N, Weiner M (2015) Net- work diffusion model of progression predicts longitudinal patterns of atrophy and metabolism in Alzheimer's disease. Cell Rep 10:359-369.

Rosen HJ, Gorno-Tempini ML, Goldman WP, Perry RJ, Schuff N, Weiner M, Feiwell R, Kramer JH, Miller BL (2002) Patterns of brain atrophy in frontotemporal dementia and semantic dementia. Neurology 58:198208.

Sadaghiani S, Scheeringa R, Lehongre K, Morillon B, Giraud AL, Kleinschmidt A (2010) Intrinsic connectivity networks, alpha oscillations, and tonic alertness: a simultaneous electroencephalography/functional magnetic resonance imaging study. J Neurosci 30:10243-10250.

Santillo AF, Englund E (2014) Greater loss of von Economo neurons than loss of layer II and III neurons in behavioral variant frontotemporal dementia. Am J Neurodegener Dis 3:64-71.

Santillo AF, Nilsson C, Englund E (2013) von Economo neurones are selectively targeted in frontotemporal dementia. Neuropathol Appl Neurobiol 39:572-579.

Saper CB (2002) The central autonomic nervous system: conscious visceral perception and autonomic pattern generation. Annu Rev Neurosci 25:433-469.

Seeley WW, Carlin DA, Allman JM, Macedo MN, Bush C, Miller BL, Dearmond SJ (2006) Early frontotemporal dementia targets neurons unique to apes and humans. Ann Neurol 60:660-667.

Seeley WW, Allman JM, Carlin DA, Crawford RK, Macedo MN, Greicius MD, Dearmond SJ, Miller BL (2007a) Divergent social functioning in behavioral variant frontotemporal dementia and Alzheimer disease: reciprocal networks and neuronal evolution. Alzheimer Dis Assoc Disord 21:S50-S57.

Seeley WW, Menon V, Schatzberg AF, Keller J, Glover GH, Kenna H, Reiss AL, Greicius MD (2007b) Dissociable intrinsic connectivity networks for salience processing and executive control. J Neurosci 27:2349-2356.

Seeley WW, Crawford RK, Zhou J, Miller BL, Greicius MD (2009) Neurodegenerative diseases target large-scale human brain networks. Neuron 62:42-52.

Sha Z, Wager TD, Mechelli A, He Y (2019) Common dysfunction of largescale neurocognitive networks across psychiatric disorders. Biol Psychiatry $85: 379-388$.

Shafiei G, Zeighami Y, Clark CA, Coull JT, Nagano-Saito A, Leyton M, Dagher A, Misic B (2019) Dopamine signaling modulates the stability and integration of intrinsic brain networks. Cereb Cortex 29:397-409.

Snowden JS, Bathgate D, Varma A, Blackshaw A, Gibbons ZC, Neary D (2001) Distinct behavioural profiles in frontotemporal dementia and semantic dementia. J Neurol Neurosurg Psychiatry 70:323-332.

Sturm VE, Brown JA, Hua AY, Lwi SJ, Zhou J, Kurth F, Eickhoff SB, Rosen HJ, Kramer JH, Miller BL, Levenson RW, Seeley WW (2018) Network architecture underlying basal autonomic outflow: evidence from frontotemporal dementia. J Neurosci 38:8943-8955.

Torok J, Maia PD, Powell F, Pandya S, Raj A (2018) A method for inferring regional origins of neurodegeneration. Brain 141:863-876.

Touroutoglou A, Hollenbeck M, Dickerson BC, Feldman Barrett L (2012) Dissociable large-scale networks anchored in the right anterior insula subserve affective experience and attention. Neuroimage 60:1947-1958.

von Economo C (1926) Eine neue art spezialzellen des lobus cinguli und lobus insulae. Z Ges Neurol Psychiatr 100:706-712.

Yang Y, Halliday GM, Hodges JR, Tan RH (2017) von Economo neuron density and thalamus volumes in behavioral deficits in frontotemporal dementia cases with and without a C9ORF72 repeat expansion. J Alzheimers Dis 58:701-709.

Zhou J, Seeley WW (2014) Network dysfunction in Alzheimer's disease and frontotemporal dementia: implications for psychiatry. Biol Psychiatry 75:565-573.

Zhou J, Greicius MD, Gennatas ED, Growdon ME, Jang JY, Rabinovici GD, Kramer JH, Weiner M, Miller BL, Seeley WW (2010) Divergent network connectivity changes in behavioural variant frontotemporal dementia and Alzheimer's disease. Brain 133:1352-1367.

Zhou J, Gennatas ED, Kramer JH, Miller BL, Seeley WW (2012) Predicting regional neurodegeneration from the healthy brain functional connectome. Neuron 73:1216-1227. 